\title{
Music as a tool for social transformation: A dedication to the life and work of Steve Dillon (20 March 1953-1 April 2012)
}

Barbara Adkins, Queensland University of Technology

Brydie-Leigh Bartleet and Andrew R. Brown, Queensland Conservatorium Griffith University

Ande Foster, Youth Plus Edmund Rice Education Australia

Kathy Hirche, Queensland University of Technology

Brian Procopis, UnitingCare Community (Lifeline)

Alex Ruthmann, University of Massachusetts Lowell

Naomi Sunderland, Queensland Conservatorium Griffith University

\begin{abstract}
This article celebrates the life and work of Australian musician and educator Steve Dillon (20 March 1953-1 April 2012). It focuses on the most significant pedagogical and philosophical ideas that informed his community music practice, and illustrates these concepts with examples from his work with the Sweet Freedom, Accessible Interactions, DIScoveringABILITIES, jam2jam and One Laptop Per Child projects. In particular, the article focuses on Steve Dillon's belief that music has profound transformative effects on people of all ages and cultures, and has the power to enable people to express themselves, build relationships and find their place in the world.
\end{abstract}

\author{
Keywords \\ Steve Dillon \\ Australia \\ community music \\ generative music-making \\ music education \\ social justice
}

\section{An opening narrative}

By Ande Foster

Two months before Steve Dillon passed away he ventured into the lush Sunshine Coast Hinterland for an unforgettable jam2jam session at the Earth Frequency Festival. On the Friday night, most of the travellers converged on the front gate after sunset. The startstop line of headlights stretched back into the dark forest, with people stepping out of cars to stretch their legs after the long journey. The first sign of Steve and his wife Angela was a radio call from the front gate. In the long wait, their car battery had gone completely flat, and couldn't be jumpstarted. There wasn't a great deal of gear to collect from their stationary hatchback, just a couple of bags, a tent and a case with the six iPads, a MacBook Pro and a microphone.

The jam2jam workshop was scheduled for dusk the following evening in the Kids' Space, which was set-up in a giant bamboo framed yurt. Steve, Ande and the jam 2jam team busied themselves with the arrangement of tables, speakers, projector and iPads in relative quiet, while the rest of the festival population was at the opening ceremony. The 
sound check began with some of the Kids' Space crew volunteering to play with the iPad controllers. They were clearly enjoying themselves. The sound check continued as some children came into the yurt, as if attracted by the sound and light. With minimal instruction and direction, the workshop was underway without pause. Steve had flagged that he wouldn't be talking much, as this set off his coughing. He mainly operated the recording and tempo controls, but eventually was drawn in to make comments and suggestions to the young people at the controls, particularly those controlling the visuals.

When the microphone came on, the population of the yurt grew. The microphone effects were predictably a huge hit. The group agreed to change the scene by starting another song, and the accompanying audio-visual creations started to take form. Beginning with each of the young people identifying their sound, and exploring their controls, Ande began to call out a few more suggestions, such as 'let's hear the bass now'. Steve hovered between the microphone and video controls, passing the microphone and giving instruction for the video and camera. His bright guitar print shirt can be seen in some of the YouTube Videos such as 'Children of the Doof' on explodingart.com.

The red light of Angela Dillon's camera moved around the Kids' Space, capturing entranced vocalists awash in echoes, dancers waving arms and spinning in front of the webcam, and young instrument controllers with multiple fingers stroking semicircular movements, their eyes on the screen. Some of the older children seemed to need a more challenging interaction, so Steve programmed a full screen of controls where all of jam2jam's instruments and parameters could be tweaked in the colourful Touch OSC system.

Familiar with these tools, and immersed in electronic music, there was nothing to stop them creating. Their inspiration was there the moment that they realized the control was in their hands. In this magical moment, Steve Dillon was passing on the keys to the next generation of electronic performers.

\section{Introduction}

By Andrew Brown

As this opening narrative shows, central to Steve Dillon's approach to community music, and life more generally, was a strong belief that "'music is and has transformative effects on people of all ages and cultures" (Dillon 2007: 219). His projects and research were guided by a conviction about the power of music to enable people to express themselves, to build relationships and find their place in the world.

Understanding the importance of musical experience, and thus better understanding their significance and how to design for them, was a lesson Steve derived from the philosophical writings of John Dewey, in particular from his notion of art as experience (Dewey 1970, 1989). Dewey highlighted the duality of art as object and art as process. He focused attention on the acts of artistic practice and aesthetic appreciation as fundamental to understanding the creative arts and their role in our culture. 
Another important influence on Steve's understanding of the experiential nature of music was Mihaly Csikszentmihalyi's (1992) theory of Flow. Flow theory focuses on optimal experience, a state of personal satisfaction and pleasure, which is particularly reliant on achieving a balance between the skills one has and the challenges one faces. This insight was a strong driver of Steve's pursuit to design musical interactions that provided access to flow experiences, especially for those with limited musical experience.

A third intellectual contributor to Steve's work was the writing of theologian and philosopher Martin Buber (1969) whose form of existentialism focused on differing types of relationships. These included interpersonal relationships between people, and those between people and inanimate things such as natural and technological objects. Buber's work emphasized the responsibilities present in relationships, especially those where power inequities existed - such as in educational and caring contexts - and the need to recognize the wholeness of others one relates to. He wrote that 'any education worthy of the name is the education of character' (1969: 104). This ethical relational framework was always at the forefront of Steve's mind as he developed and conducted the community music projects featured in this article.

All these and many other influences came together for Steve in the theory of Meaningful Engagement that he developed with Andrew R. Brown (Dillon 2009). This theory explored the range of ways people interact with creative activities; including musicmaking. Interactions occur through different modes of engagement, such as being a listener or a player, and at different contextual layers, from the personal to the cultural. In particular, Steve was concerned with the potential for an activity to be meaningful at each of three contextual layers. To be able to experience personal meaning through an individual relationship with music, social meaning through the wordless connection with others through music, and cultural meaning through being recognized and valued by the community for their music-making efforts. In an ideal music project there would be opportunities for interactions and participation across many modes of engagement and for meaning to arise at all contextual layers.

Another feature of the community music projects that Steve involved himself with was their reliance on technologies. He believed, following Marshal McLuhan (1964) and Martin Heidegger (1977), that technologies mediated most interactions and relationships and, harnessed appropriately, they could be used to reveal and enhance a person's musicality. This could be as simple as using a microphone to amplify a voice or using a generative algorithm to turn a gesture into a melody. The Network Jamming project that Steve led during the 2000s further developed the jam2jam software that put these ideas into practice and formed the basis of many different community music projects, discussed in this article. ${ }^{1}$ Technologies such as CD, Skype, YouTube, websites and social media were widely used in Steve's projects to communicate and disseminate the outcomes; further extending their impact and contributing to the opportunities for cultural meaning through feedback, social meaning through collaboration and personal meaning through reflection. Perhaps most importantly for Steve, a rich media environment and the technologies that supported it ensured that projects involved 'conversations about music with the music present', as he liked to say. The examples that follow highlight how these 
ideas manifested themselves in the community-driven projects Steve was involved with.

\section{Social justice and community music through Sweet Freedom}

By Naomi Sunderland and Brian Procopis

Steve Dillon saw community music as an inherently political and ethical enterprise, one that aims to effect social change in the interests of promoting social justice. This belief was strongly embodied in the work he did with the not-for-profit organization Sweet Freedom Inc. Sweet Freedom is a music production and promotion organizsation comprised of producers, film -makers and community development practitioners. Collaborating with people from marginaliszed circumstances, Sweet Freedom crafts songs, music videos and documentaries. It then promotes and distributes these to national and international networks in order to educate, entertain and promote solidarity. Culminating in a community festival, performances and a $\mathrm{CD} /$ Video launch, the process produces team building, and self-esteem development. The CDs serve to raise funds for the various communities and provide a mechanism for community participants to enable their voices to be heard. In addition, the CDs offer the broader public opportunities to expand their levels of awareness and understanding. In all cases, profits are returned to the communities.

Sweet Freedom draws upon creative community music activity to: Build personal, social and cultural meaning for participants and the community; Enable participants to understand their situation and build resilience; Enhance personal, social and cultural identity; and Advocate and bring attention to social justice issues through composition, performance and recording. At present Sweet Freedom is evolving from being a community music project organization into a social justice record label whose principal functions are to advance social justice and human rights through creative and artistic mechanisms crafted specifically for each unique community. Sweet Freedom seeks to document processes and outcomes, evaluate democratically ways that amplify the voices of 'the unheard' in communities experiencing marginalization and highlight the elements of resilience within the experiences of the participants. Sweet Freedom also presents initiatives online as examples of ethical ways of conducting projects together with ways of evaluating outcomes. The goal is to provide access to resources for others through the website while promoting the shareable outcomes of all Sweet Freedom activities.

A request came through from the Down Syndrome Association of Queensland for a song to be composed for the youthful members to celebrate a special occasion. The volunteers who had founded Sweet Freedom clarified quickly that we do not write songs for people - we write songs with people. We subsequently had meetings with the children and young adults with Down syndrome who would participate and their parents and siblings. We talked about the song. They wanted it to be up-tempo and proud. Parents wanted the broader public to see their children as they saw them - as productive members of society with their own unique gifts to offer - not as victims to be just cared for by others. We asked one question of the children: 'what do you love about your life?' Their responses came quickly; these were active kids with their own passions and interests. The resulting song 'My Life My Voice' took shape over five consecutive meetings. The draft lyrics were brought back each time and submitted to the group for checking. Changes were 
made when the songwriter did not quite get it right. There were lines for individuals to sing and there was a chorus for everyone to join in singing. There was also a 'na na na' section for those with limited language capacity. We practised and practised. Repetition is comfortable territory for the participants with Down Syndrome because it meets the need for familiarity and security. Any of us who felt the stirrings of exasperation when one or other of the participants called out excitedly 'again' just had to get over it. This process was not about us it was about the performers. Having no funding to cover the recording phase of the project, Sweet Freedom contacted Steve. Founding Chair Brian Procopis had met Steve once or twice before and recognized a kindred spirit. Predictably Steve responded with enthusiasm to our request for assistance with a commitment to provide a producer/recording engineer and studio facilities. Steve organized a weekend for us in the Queens University of Technology (QUT) studio and provided groups of five children, their siblings and parents with a recording time slot. He also arranged a volunteer guitarist and drummer to accompany the children's singing. It was unchartered territory for the QUT team. We witnessed a special moment as the younger ones spontaneously hugged Steve whom they had met only twenty minutes before. Steve was entranced as were the other members of his team. We suspect that this was the moment when Steve internalized a commitment to Sweet Freedom.

Steve's professionalism and experience as a singer and community music facilitator came to the fore during this recording session. He quickly recognized that people with Down Syndrome often experience limited vocal capacity: low muscle tone is very common as are hearing difficulties and speech problems. Steve discussed the children's needs with Russell the producer (one of Steve's students): 'Should we use auto-tune?' They made a decision quickly: 'No let's keep it authentic... let's offer the singers the opportunity to sing their lines as many times as they need - we'll use their best effort'. It was a respectful compromise that involved more work for Russell who recorded more than 100 tracks during the session. Everyone loved the result. The children were ecstatic and extremely proud of the song they created and now owned. The resulting DVD is now given as a gift to bewildered and distressed parents whose child has just been diagnosed with Down Syndrome. It is also given to schools to augment their efforts to create an inclusive culture. This project was the inaugural involvement for Steve into the vision and practice of Sweet Freedom. He became Sweet Freedom's ambassador and, in time, co-chairperson. Steve never forgot those children. He remained involved in their projects, absorbed their wisdom and vitality and shared his own joie de vivre with them. It was and continues to be the proverbial exchange of gifts.

Steve liked what he saw when he came across Sweet Freedom but saw much more than its founders initially did. He recognized Sweet Freedom's potential for national and international relevance and set about implementing a master plan to develop Sweet Freedom into a social enterprise and social justice record label.

Under Steve's initiation, Sweet Freedom was selected as one of 55 international community music projects to be listed in a 2010 United Nations' Compendium 'Music as a Natural Resource: Solutions for Social and Economic Issues'. The Compendium was part of a series recommended during the 'Age of Connectivity: Cities, Magnet of 
Hope...Imagining the Possible' United Nations High-Level Working Sessions. The Music as a Natural Resource Initiative sought to promote music as a key way of achieving the UN's goals for community, social and economic development. The 55 projects presented in the Compendium were selected from 33 countries and two multinational organizations. The UN stated that the selected projects showed 'that music is being used throughout the world to successfully address critical social, health and economic issues and can adapt to local culture and conditions' (United Nations 2010: XIV).

Steve also took an active role in developing the ethical and evaluative aspects of Sweet Freedom as co-chair; he participated in several projects as a co-worker and researcher/observer endeavouring to use Web 2.0 technology as a means to promote and document Sweet Freedom's work. Steve also began the process of sharing the Sweet Freedom story with the world through his academic writing and presentations. In all cases, Steve pursued collaborative, ethical and respectful relationships with participants and colleagues involved in Sweet Freedom projects as he set about establishing a rigorous academic and evaluative framework for our work.

Steve's collaborations with Brian Procopis and others involved in Sweet Freedom led to a number of ideas that he shared via his academic publications and presentations. We summarize some of the key ideas here.

Connections: Steve's work with Sweet Freedom emphasized the way that music connects people, enabling them to harness energies, focus their intention and create new links between cultures. Through Sweet Freedom Steve saw an opportunity to create a climate that was conducive to the expansion of social capital and a subsequent precursor to social change (see Procopis and Dillon 2011).

Choral autoethnography: Extending on Bartleet and Ellis (2009) Steve and Brian Procopis used a method of 'choral autoethnography' to present research in a way that would help musicians to 'examine, understand and communicate the personal ideas behind their creative experiences' (Procopis and Dillon 2011). Steve saw that collaborative community song writing with the participants in Sweet Freedom projects provided an opportunity to extend the 'choral' metaphor to amplify community music participants' voices and experiences as research 'data'.

Songs of resilience: Steve argued that Sweet Freedom provided an example of how 'songs of resilience' (see Brader 2011) can be moved great distances from their origin as utterances of personal experience and identity to being international resources for social justice. Steve's ambassadorial and academic contributions to Sweet Freedom with organizations such as the United Nations and international community music networks ensured that our work and our participants' voices reached wider audiences than we could have ever imagined.

Salutogenic music, social justice, and social change: Steve's work with Sweet Freedom primarily focused on 'salutogenic' (Antonovsky 1996) community music-making: ways 
of using music to produce a general state of wellness and happiness rather than as a 'therapy' for a particular malady or experience. In the closing to one of his most recent Sweet Freedom related publications, Steve made the following appeal to us all:

To identify a causal link between music making and human resilience we must constantly strive to identify the qualities of music making that serve the cause of social justice and offer opportunities for the voices of the unheard to both educate and beckon a compassionate response from all. (Procopis and Dillon 2011: 181)

In this one statement, Steve summarized the vital and deep concepts that underpinned his approach to community music. He saw in music itself a quality that could both open people's minds and hearts to 'the other' and communicate rich stories of experience in a way that could not only shift mindsets but evoke an active response. We commit to uphold the spirit and dedication of Steve's vision and contribution to community music via Sweet Freedom.

\section{Digital tools as resources in musical participation for people with disabilities} By Barbara Adkins

As the aforementioned example of Steve Dillon's work with Sweet Freedom shows, he was committed to research that enhances the capacity of digital tools to support musical participation by people with disabilities, motivated by strong social justice principles. In particular, he had a deep understanding of what is at stake in providing access to improvisational music- making for people with intellectual disabilities. As Finlay et al.'s (2007) conversation analytic study has shown, the experience of 'not being noticed' can inhabit the turn-by-turn process in spoken interaction for this group where gestures, sounds and other phenomena can be passed over as turns at talk. Steve's response to this - 'Don't Speak for me. Allow me to speak for myself!' was behind the enormous energy and insight he invested in his work in this area. Our research together was fired by this strong commitment. We worked on two key projects related to this research: Accessible Interactions, and DIScoveringABILITIES

Steve was a driving force behind our use of jam2jam in the 'Accessible Interactions' project funded jointly by the Australasian Collaborative Research Centre for Interaction Design and the Endeavour foundation - an Australian not for profit organization specializing in services for people with intellectual disabilities. The researchers ${ }^{2}$ observed the potential for jam 2 jam to offer new creative collaborative and improvisational experiences for the service users at Endeavour. Their stories revealed great enjoyment in listening to and downloading music, dancing and singing. However, at home music was often experienced as a sole activity. At service centres, music was fun but followed the format of songs and actions.

Jam2jam offered the service users an apparently novel opportunity for engagement through collaborative improvisation. Steve drew on the stories from the field and inspired an approach to the experience of music improvisation on the part of service users at Endeavour that supported new experiences of recognition. Our research helped us put a finer point on some of the crucial properties of digitally supported music collaboration in 
enhancing music participation for people with disabilities. In particular, we found that digital music improvisation tools can provide opportunities for participants to develop and assert their own definitions of normality and ability in and through collective aesthetic agency.

Our observations of the use of jam 2 jam by people with intellectual disabilities at Endeavour found that most participants intuitively experimented with the up and down motion of the sliders, identifying the differences they could produce in the music by using these controllers. Over the course of the first session, and sometimes with encouragement and/or direction from research team members, they began to move individual sliders to other positions between the far top and bottom, discovering the possibilities for making subtler differences.

After initial exploration, individuals displayed different orientations to observing, exploring and experimenting with Jam2jam. For example, one service user emulated a 'DJ-style' engagement with the sliders, others experimented with knobs and buttons, others watched the screen for long periods of time and others engaged with each other displaying an interest in and/or directing what co-participants were doing.

The video, in particular, provided for an engaging and collaborative atmosphere between participants - both those directly 'using' jam2jam and those 'observing' from the background. Participants controlling the video function showed a particular orientation to exploring and experimenting with kaleidoscope effects, particularly when these captured and integrated their images in the context of music-making. The video encouraged participation through moving hands and bodies in ways to achieve different effects in the kaleidoscope. For example, participants would manipulate their bodies in order to produce multiple views of themselves, create up-side down views, create images appearing as though their heads and limbs were joined together, etc. Sometimes they would simultaneously move their arms and bodies to the beat to create a group affect, often accompanied by group cries of enjoyment when a particular outcome was achieved.

In one case, the music and video features of the tool successfully engaged a service user who had displayed no direct interest in the tool, preferring to do her exercises at the back of the room. Over time, she was observed to begin performing her exercises to the beat of the music and slowly moved towards the group as she realized that she was visible on the screen, creating a subtle dance performance. Another service user was noted by a staff member as uncharacteristically pulling her down so that her image could be captured on the screen. The analysis of the musical interactions in this setting pointed to the capacity of digital tools to enhance musical experience through improvisation, and raised questions about the way these tools might be used as an additional resource in service provision for people with intellectual disabilities more generally. Steve's work with Down Syndrome Association Queensland (DSAQ) on the DIScoveringABILITIES project, provided an opportunity to investigate this question.

Steve successfully led an application for funding from the auDA ${ }^{3}$ foundation: a charitable trust established to promote and encourage educational and research activities to enhance 
the utility of the Internet for the benefit of the Australian community. Steve's vision for this project was to develop an interactive Internet music therapy and community music performance system that enables music experiences for young Australians with Down Syndrome in urban and remote locations. This project is still ongoing. To date observations have identified the potential of digital tools to be integrated into broader music therapy activities and processes, which at DSAQ, included fostering song writing and composition. A highlight of the observational data is evidence of the potential of the digital tool not only to support improvisational music-making but also to inspire and promote this improvisation through voice and other instruments. Steve's recent report observed that of particular note in the data collection cycles was the improvisation activity with songwriting with members writing words for jam2jam scenes and improvising them in each session. Further, the capacity to use jam2jam on iPads and to conduct performances from multiple locations using Skype shows great promise in addressing a crucial issue in the lives of many people with intellectual disabilities: isolation. Steve's commitment to extending access to collaborative music experience on the part of homebound and regionally isolated families will be explored and documented as part of the next phase of the project.

\section{Music-making and learning experiences through jam2jam and meaningful engagement \\ By Kathy Hirche}

As the previous example has shown, Steve Dillon was the leader of an ongoing study of the suite of jam 2 jam generative music systems. He firmly believed that digital technology can be a vehicle by which users can express themselves musically in much the same way as by playing a traditional musical instrument. He stated that, "'The act of making music in groups forms relationships"' (Dillon and Hirche 2010: 190), and suggested the experience of playing music with others is the key to what he called social meaning (Dillon 2001). It is not the process of becoming proficient at playing a particular instrument, but rather what they are able to experience once they have attained a certain level of proficiency, that allows them these "special"” experiences. Traditionally, experiences such as this are restricted to those who are proficient enough on a musical instrument to effectively participate. The jam2jam generative music software discussed above enables even novice users to contribute to improvising, composing and performing activities. The name "jam2jam"” brings to mind the term " jamming"” as it refers to musicians creating music together by way of spontaneous improvisation. This term also has fun, playful connotations. Jam2jam can be used across a network in order to create a virtual ensemble. "'Observations of a variety of age groups, contexts and cultural groups using jam2jam suggests that the virtual social meaning shares the same qualities as a "real"" ensemble experience",4 (Brown and Dillon 2007: 99).

Brown and Dillon (In Press) claim that 'generative systems provide a particularly useful scaffolding that allows either direct or meta-level control of the generated music and allows for intermittent interaction and listening that can support cognitive musical development'. What distinguishes generative music systems is that they involve 'a computer program, a machine, or other procedural intervention, which is set into motion with some degree of autonomy contributing to or resulting in a completed work' 
(Galanter 2003). Rule-based musical algorithms are used in software such as jam2jam to create cyclic musical output that can be manipulated by the user(s) to create varying results. ${ }^{5}$ In the case of jam $2 \mathrm{jam}$, the scaffolding involves embedding theoretical music knowledge and rules associated with particular musical styles, ensuring that the results will be in accordance with the theory and rules regardless of the interactions of the user. This then frees the user to operate without fear of failure. 'This raises the question of the nature of the insights, skills and processes required for users to explore their creativity and capacity for collaborative music making in this context' (Adkins et al. 2007: 3).

Software trials in the form of 'PowerJam' Workshops have been part of the Powerkidz programme for free and low-cost children's activities at the Brisbane Powerhouse ${ }^{6}$ since 2005 (see Figure 1). These trials have served both as a testing ground for developments to the software and an opportunity to observe at close range the phenomenon of meaningful musical engagement with jam2jam. In these workshops, jam2jam software and Apple laptops were used to create virtual ensembles in which the computers are effectively used as instruments and it was observed that interaction with the software provided an environment in which participants spontaneously create music and in doing so develop a relationship with musical materials and other participants (Adkins et al. 2007).

\section{INSERT FIGURE 1}

Figure 1: Powerkidz 2008 featuring Steve Dillon (far right)

During the last ten years, the original jam2jam software has evolved into to a suite or family of software that includes:

- jam2jam gray (the original version, with a mixer-like interface)

- jam2jam AV (enabling the manipulation of both audio and visual parameters)

- jam2jam XO (for the One Laptop per Child computer), as discussed below.

\section{INSERT FIGURE 2}

Figure 2: Input and Output options of jam2jam (Brown 2010).

As illustrated in Figure 2 there are various input and output options available with jam2jam AV (Brown 2010: 85). These options cater for a large range of contemporary musical activities using contemporary musical styles (Brown 2010).

Jam2jam's graphic interface gives the user a visual representation of audio parameters that is capable of:

- showing the parameter control input of the user(s) in real time

- being a static 'picture' of the audio parameters that will remain unchanged until further input from the user(s) and

- displaying a silent 'picture' of the audio parameters that can be viewed as either a static or moveable model of the sound.

These features mean that jam 2jam may be of assistance in various ways in which reflection is already used, and also offer new ways to encourage reflective practice in 
learning environments and enable 'music to be present in a conversation about music' (Dillon 2007: 78).

Burnard and Dillon's UK study involving Year 9 high school boys confirmed that jam2jam 'is a useful tool that enables the kinaesthetic exploration of musical elements' and that 'it promotes communication between its users not just through the exploration of its facilities, but also in performance' (2010: 6). Though longer in duration than the PowerJam Workshops, ${ }^{7}$ Burnard and Dillon's study was still a one-off event for the participants. Havre's (2011) study in Norway focused on Year 7 students used jam2jam for several sessions. ${ }^{8}$ Whilst the major focus of this study was the students' interaction during online jamming, she suggests that 'skills in communication and in social interactions are developed as well as in music' (Havre 2011: 102).

The design of the PowerJam Workshops made use of headphones to allow for individual and/or small ensemble experiences for users within the same room, and also made use of a PA system and audience seating. This helped to define the three experiential contexts of Personal, Social and Cultural (Dillon 2001). The Personal (or private) phase in which a relationship with the musical materials was established, was followed by the Social interaction (characterized by collaborative learning) and acknowledgement of real musical outcomes of the participants' endeavours in both of these phases at the cultural level. In all three of these contexts, the activity was largely self-initiated and selfdirected. The computer and networked system provided an open and encouraging framework for interaction, whilst the coach/teacher's role shifted from behavioural management to a musical discourse with participants.

\section{INSERT Figure 3}

Figure 3: Meaningful Engagement Matrix.

Developed as an observational tool, the Meaningful Engagement Matrix (Dillon 2006) has been used by Brown, Dillon and other researchers when reviewing video data from trials of jam2jam (see Figure 3). According to Dillon, 'the notion of determining meaningfulness and engagement requires a much more substantial evaluation of a whole context and stakeholders beyond the activity and teaching method, and extends to how the child perceives and values the experience in a particular context' (2005: 338). The combination of Dillon's three types of meaning with Brown's (2000) five modes of Modes of Creative Engagement generated a matrix with which to determine meaningful engagement.

The elements of Brown and Dillon's Meaningful Engagement Matrix are not entirely separate, in the sense that the presence of one may depend upon the presence of another or several others. Operation in or via one mode does not preclude simultaneous operation in other modes. A teacher or music-making facilitator conversant with the Meaningful Engagement Matrix could use it to illustrate an overview of the modules experienced by participants in any music learning experience (whether the experience involves jam2jam or not). 'While we study how the music is created, we also simultaneously study how the participants learn how to create music' (Folkestad 1996: 59). The examination of 
jam2jam experiences during the PowerJam Workshops revealed value for music learning and teaching that suggests jam2jam provides a concrete experience that encourages a discourse around creative production between peers and teachers/coaches. This aspect of reflection through action (Schon 1983, 1987), with the computer instrument enabling a concrete demonstration of what we know and can do, has potential to increase the opportunity for and quality of reflection on creative experience. Jam 2 jam has the potential to frame and focus experiences in such a way that they activate and give access to a form of collaborative creativity that encourages expressive music-making and positive social interaction.

\section{Open source philosophy, music education and the development of jam2jam XO} By Alex Ruthmann

One of the projects Steve recently finished documenting was the development of perhaps the most successful version of jam $2 \mathrm{jam}$ - jam $2 \mathrm{jam} \mathrm{XO}$. As of this writing, there have been over 34,000 downloads of this version of jam2jam. Jam2jam XO was developed for the One Laptop Per Child (OLPC) XO computer - an inexpensive computer designed by the MIT Media Lab as a catalyst technology to bring access to modern communication and the Internet to children everywhere. Steve's passion for the potential of technology in increasing access to music- making experiences of all forms fit well with the philosophy of the OLPC project.

The OLPC project was initiated as a fully 'open source' project, in that the operating system and software for the computer were developed in an open environment where anyone with computer programming skills could view the code, modify it for free, add to and extend the features and functionality. This was important because the system needed to be easily fixable and adaptable by children and local developers, many of which were located in remote areas without access to professional repair technicians.

One of the limitations of the primary version of jam $2 \mathrm{jam}-\mathrm{jam} 2 \mathrm{jam} \mathrm{AV}$ - was that it could only be run on an expensive Apple computer with a powerful processor. This version was great for use in well-resourced communities and schools, but it did not scale well to developing countries, the primary market for the OLPC project. Steve, working together with lead developer Thorin Kerr and project associate Andrew R. Brown, engineered ways to fit much of the advanced technology and functionality of jam2jam AV into the OLPC XO version of jam2jam, which ran on a processor with less computing power than today's common smartphones.

Jam2jam XO preserved the network jamming capabilities of earlier versions so that four OLPC XO users could engage in ensemble music-making experiences together but modified the organization so that each computer user took on a single instrumental role, rather than any user potentially controlling all instruments as in previous versions. Jam2jam XO also harnessed the same generative algorithm technologies (Brown and Kerr 2009) to engage the user as a partner in the music-making process, rather than simply using the technology as a tool (Brown and Dillon 2012). Simple physical gestures on the trackpad were mapped to changes in the soundscape of the music through adjusting density, timbre, duration, tempo, volume and other broad musical parameters. 
Steve always stressed that jam2jam was a performance technology and not a production technology. Through these design features of jam $2 \mathrm{jam}$, novice users could engage as ensemble performers, improvising with sound, music and image in collaborative ways together in person and virtually over the Internet.

For Steve, the open source philosophy behind the development of the OLPC had implications beyond the design of the technologies behind jam2jam. What mattered most was the application of the underlying open source philosophies to music education, engagement and experience design.

The aspects of open source philosophy that were successfully adopted by the developers, researchers, teachers and students who have actively used jam2jam XO directly mirror those of the OLPC project:

- The software and support resources are freely available

- The use of the technology supports learning objectives

- Musical group work is facilitated through collaborative network jamming and

- Resources are shared amongst developers, researchers and educators (adapted from Sugar Labs n.d.)

Steve saw jam2jam XO as open source in several ways. In the most basic sense, the source code was freely available and could be changed and adapted by anyone with programming expertise. Second, new musical style scenes could be composed and shared. Third, Steve applied the metaphor of learning recipes ${ }^{9}$ to the sharing of ideas for the use of jam 2 jam among members of the user community - including teachers, community music facilitators and students. Recipes included sharing ingredients (resources), methods and processes (pedagogy) and nutritional value (knowledge or social outcomes) (Dillon in press). Steve saw these open source practices and philosophies as contemporary extensions of the progressive and pragmatist philosophical and pedagogical ideas promoted by Martin Buber, John Dewey and Jerome Bruner as outlined above in this article.

These applications of open source ideals inspired Steve's forthcoming paper - 'An open source approach to music education through jam2jam XO' (Dillon in press). This paper is part of a special issue of the Journal of Music, Technology, \& Education, where Steve served on the editorial board. The idea for this special issue started back in 2010 with the planning of a symposium on the application of 'open source' philosophies to music education at the International Research in Music Education (RIME) Conference held biennially at the University of Exeter. The presentations at this symposium turned into a call for papers for JMTE, for which Steve served as a guest editor.

Steve's contribution to this special issue presents many issues of relevance to those working in music education, music technology and community music. He argued that simply adopting open source software was not enough. What should be learned from open source practices is how to facilitate democratic engagement of participants within an interactive community. Steve's analysis of how users contributed to the ecosystem 
around jam 2 jam revealed that contributing recipes was the only open source aspect actively taken up by the users of jam2jam XO. Changing the source code was complex and required specialized knowledge, while sharing 'recipies' for jamming activities was more widely achievable. Steve also made the point that the intended users of jam 2 jam $\mathrm{XO}$ were not assumed to be developers. Though users had the ability to design new musical scenes, most rather consumed than created original musical content.

Steve argued that, instead, it was the qualities of exploration, sharing and documenting that should be foremost in the development of learning experiences both about and through music.

The teacher's role is to interpret the educational affordances of music technologies and to seek the opportunity to widen access and deepen experience. It seems that even after a century of philosophers of education extolling the virtues of experiential, student-centered learning that mimetic approaches are still the predominant mode of delivery of education. Drill and practice and surveillance software base their design on mimetic models of interaction with students. Open source practices potentially provide us with a design model that includes exploration, democratic participation, sharing, collaboration and clear evaluation. (Dillon in press)

Steve envisioned jam 2 jam being used by children and adults in school- and communitybased settings as a way of engaging in ensemble music-making for those without traditional formal instrumental skills. He recognized the role that creative music technologies play in the performance and production of music valued by children. His work in the development and dissemination of jam 2 jam harnessed and built upon those technologies to increase access to music-making and expression for thousands of children. Users of jam2jam interacted together over the Internet, at music festivals, academic conferences, community arts venues and schools across the world. Some of the strongest communities of users continue today across Australia, Sweden, Uruguay, United States, United Kingdom and Hong Kong.

\section{Conclusions}

As these examples of Steve Dillon's work have shown, for him music was a particularly democratic medium. Not because its practices dissolved levels of skill and complexity, but because music-making transcended other communication methods and involved a wordless knowing of others that became a basis for relationships and interactions in any social context (Dillon 2010). This resonates strongly with his vision of 'relational pedagogies' that focus not on the individual concerns of the teacher, student, music or technology, but rather on the relationships developed interactively among all involved in the music-making process (Ruthmann and Dillon in press). The extensive cadre of musicians, teachers and children who have had, and will continue to experience these musical relationships through projects such as Sweet Freedom, Accessible Interactions, DIScoveringABILITIES, jam2jam and One Laptop Per Child serve as a fitting testament to the impact of Steve's passion for meaningful music-making for all.

\section{References}


Adkins, B., Dillon, S., Brown, A. R., Hirche, K. and Gibbons, C. (2007), 'The role of generative arts in supporting cultural participation: A conceptualisation of the jam2jam network jamming tool', paper presented at the 13th International Conference on Virtual Systems and Multimedia. Brisbane, Australia (VSMM'07).

Antonovsky, A. (1996), 'The salutogenic model as a theory to guide health promotion', Health Promotion International, 11, pp. 11-18.

Bartleet, B. and Ellis, C. (eds) (2009), Music Autoethnographies: Making Autoethnography Sing/Making Music Personal, Brisbane: Australian Academic Press.

Brader, A. (ed.) (2011), Songs of Resilience, Meaningful Music Making for Life Series, Book 3, Newcastle upon Tyne, UK: Cambridge Scholars Publishing.

Brown, A. (2000), 'Modes of compositional engagement', paper presented at the Australasian Computer Music Conference, July 6-9 2000, Brisbane.

Brown, A. R. (2010), 'Network jamming: Distributed performance using generative music', in proceedings of the New Instruments for Musical Expression Conference 2010, June 15-18 2010. University of Technology Sydney, Sydney.

Brown, A. R. and Dillon, S. (2002), jam2jam, [computer software] Brisbane: Exploding Art Pty Ltd.

(2007), 'Networked improvisational musical environments: Learning through online collaborative music making', in J. Finney and P. Burnard (eds), Music Education with Digital Technology, New York: Continuum, pp. 96-106.

(2012), 'eBILITY: From tool use to partnerships', Journal of Music Technology in Education, 4:2 and 3, pp. 201-15.

(in press), 'Collaborative digital media performance with generative music systems', in G. MacPherson and G. F. Welch (eds), The Oxford Handbook of Music Education, New York: Oxford University Press.

Brown, A. R. and Kerr, T. (2009), 'Adaptive music techniques', in A. Sorensen (ed.), Improvise: The Australasian Computer Music Conference, Brisbane: Australasian Computer Music Association, pp. 26-31.

Buber, M. (1969). Between Man and Man. Trans and Introduction by Ronald Gregor Smith. London: FontaBeacon Press.

Burnard, P. and Dillon, T. (2010), Collaborative Learning and Exploratory Playing with Jam2jam Research Report 09-10 Cambridge Jamming Project, Cambridge: University of 
Cambridge.

Csikszentmihalyi, M. (1992), Flow: The Psychology of Happiness, London: Rider Books.

Dewey, John (1970), Experience and Education, USA: Collier-Macmillan.

(1989), Art as Experience, USA: Pedigree Books.

Dillon, S. C. (2001), The Student as Maker: An Examination of the Meaning of Music to Students in a School and the Ways in Which we Give Access to Meaningful Music Education, Melbourne: La Trobe.

(2005), 'Meaningful engagement with music technology', in E. MacKinlay, D. Collins and S. Owens (eds), Aesthetics and Experience in Music Performance, Newcastle, UK: Cambridge Scholars, pp. 329-41.

(2006), 'Jam2jam: Networked improvisational musical environments', in B. W. Leung and M. Moore (eds), School Music and Teacher Education: A Global Perspective in the New Century, Hong Kong: Department of CAPE, the Hong Kong Institute of Education \& International Society for Music Education, pp. 1930.

(2007), Music, Meaning and Transformation, Newcastle, UK: Cambridge Scholars Press.

(2009), 'Examining meaningful engagement: Musicology and virtual music making environment', in E. Mackinlay, B. L. Bartleet and K. Barney (eds), Musical Islands: Exploring Connections Between Music, Place and Research, Newcastle upon Tyne: Cambridge Scholars Publishing, pp. 297-310.

(2010), 'Music is a wordless knowing of others, resilience in virtual ensembles', in A. Brader (ed.), Songs of Resilience, Newcastle upon Tyne: Cambridge Scholars Publishing.

(in press), 'An open source approach to music education through jam2jamXO', Journal of Music, Technology and Education.

Dillon, S. and Hirche, K. (2010), 'Navigating technological contexts and experience design in music education', in J. Ballantyne and B. L. Bartleet (eds), Navigating Music and Sound Education, Newcastle upon Tyne: Cambridge Scholars Publishing, pp. 175-92.

Dillon, S., Adkins, B., Brown, A. R. and Hirche, K. (2008), 'Communities of sound: Generative music making and virtual ensembles', International Journal of Community Music, 1:3, pp. 357-74. 
Folkestad, G. (1996), Computer Based Creative Music Making: Young People's Music in the Digital Age, Gothenburg: University of Gothenburg.

Galanter, P. (2003), 'What is generative art? Complexity theory as a context for art theory', paper presented at the GA2003 - 6th Generative Art Conference, Italy.

Havre, S. J. (2011), 'Play to learn', unpublished Master's thesis, Bergen University College, Bergen.

Heidegger, M. (1977), The Question Concerning Technology and Other Essays, New York: Harper \& Row.

McLuhan, M. (1964), Understanding Media: The Extensions of Man, London: Sphere Books.

Procopis, B. and Dillon, S. C. (2011), 'Voices of the unheard', in A. Brader (ed.), Songs of Resilience, Meaningful Music Making for Life Series, Book 3, Newcastle upon Tyne, UK: Cambridge Scholars Publishing, pp. 165-83.

Ruthmann, S. A. and Dillon, S. C. (in press), 'Technology in the lives and schools of adolescents', in G. McPherson and G. Welch (eds), Oxford Handbook of Music Education, Vol. 1, New York: Oxford University Press.

Schon, D. A. (1983), The Reflective Practitioner: How Professionals Think in Action, New York: Basic Books.

(1987), Educating the Reflective Practitioner: Toward a New Design for Teaching and Learning the Professions, San Francisco: Jossey-Bass.

Sugar Labs (n.d.), 'Education goals', http://sugarlabs.org/index.php?template=page\&page $=$ contributors. Accessed 1 April 2012.

Swanwick, K. (1979), A Basis for Music Education, Windsor: NFER.

United Nations (2010), Compendium of Music as a Natural Resource: Solutions for Social and Economic Issues, Manhattan, NY: United Nations Headquarters, http://unpan1.un.org/intradoc/groups/public/documents/undpadm/unpan042585.pdf

\section{Contributor details}

Barbara Adkins (Ph.D.) is an Associate Professor in Sociology at the Queensland University of Technology, Australia. She is also senior social scientist at the Australasian Cooperative Research Centre for Interaction Design (ACID). Her 
current research examines conceptual and methodological approaches to sociocultural aspects of interaction and urban design.

Dr Brydie-Leigh Bartleet is a Senior Lecturer at the Queensland Conservatorium Griffith University. She was Research Fellow on the Australia Research Council-funded project Sound Links (2007-2008), which examined the dynamics of community music in Australia. Her current research projects include an Australia Research Council-funded project Captive Audiences (2011-2012) that explores performing arts rehabilitation programmes in prisons, and an Office for Learning and Teaching funded project Enhancing Indigenous Content in Performing Arts Curricula Through Service Learning with Indigenous Communities (2011-2013). She is a Commissioner on the International Society for Music Education's Community Music Activities Commission, the Councillor for Research on the Music Council of Australia and serves on the editorial board of the International Journal of Community Music.

Andrew R. Brown is an educator, researcher, musician and author. He is Professor of Digital Arts at the Queensland Conservatorium in Brisbane, Australia and his academic expertise is in technologies that support creativity and learning, computational music and art, and the philosophy of technology. Andrew's creative activities focus on real-time audio-visual works using generative processes and live-coding performances. He is the author of the book Computers in Music Education: Amplifying Musicality, published by Routledge in New York.

Ande Foster is the Music Youth Worker at Gympie Flexible Learning Centre, a part of the Youth Plus national programme for young people at risk of disengaging from education. The music programme is based on accessible forms of music creation chosen by the young people including computer composition, DJing, MCing, multimedia, drums and guitar. Ande Foster became involved with the Jam2Jam project after a long relationship with Steve Dillon and Andrew Brown, presenting guest lectures on Music and Spirituality, Multimedia Music and Sex Drugs and Rock and Roll, drawing on underground dance music experiences from the Australian, Japanese and European Scene.

Kathy Hirche is a music teacher and professional musician who has recently completed a Masters degree at QUT (Brisbane). Steve Dillon was her principal supervisor. Kathy was employed as a research assistant during several jam2jam software trials, and had significant input regarding development of the software interface and experience design of the workshops. She also co-authored several articles and book chapters with Steve Dillon during the course of her study at QUT. Currently, Kathy divides her time between teaching, performing and furthering her own study.

Brian Procopis is currently the Coordinator of Community Development Programs for UnitingCare Community (Lifeline). Involvement in such music-based esteem-building programmes as the Zillmere School 'Aim High/From Little Things Big Things Grow' initiative, 'Kidz2Kidz' with Brisbane-based Iraqi children affected by the ongoing conflict in their homeland, 'My Life My Voice' celebrating the lives and contribution to 
broader society of children with Down syndrome, the Urandangi Aboriginal community who sing that whenever they go away 'Urandangi Calls Me Home', the Transformers (Brisbane version of the 'choir of hard knocks') and Scattered People where music is taken to the 'boat people' in the Pinkenba Detention Centre to provide a safe place where 'our humanity can intermingle with theirs and where traumas can be softened' brought Brian and his vision for Sweet Freedom as a record label founded on the principles of social justice, social inclusion and community development into the enthusiastic perimeter and kindred-spirited passions of Steve Dillon.

Dr S. Alex Ruthmann is Assistant Professor of Music Education at the University of Massachusetts Lowell where he teaches graduate and undergraduate courses at the intersection of music education, arts computing and research. He currently serves as President of the Association for Technology in Music Instruction, Chair of the Creativity special research interest group of the Society for Research in Music Education, as managing editor of the International Journal of Education \& the Arts, and serves on the editorial/advisory boards of the British Journal of Music Education, International Journal of Music Education: Practice, and the Journal of Music, Technology, and Education. His current research explores new media musicianship and creativity, and the development of technologies for music learning, teaching and engagement for use in schools and community-based interdisciplinary arts + computing programmes, funded by the National Science Foundation.

Dr Naomi Sunderland is currently Project Manager for the national Australian Teaching and Learning Council Community Service Learning Project led by the Queensland Conservatorium at Griffith University. Dr Sunderland has a background in social research for health and well-being and creative narrative and ethnographic approaches to representing lived experience of disability and social determinants of health.

Contact:

Barbara Adkins, Gardens Point, D Block, Room 525, Creative Industries Faculty, School of Design, Queensland University of Technology, Brisbane, Australia.

E-mail: b.adkins@qut.edu.au

Brydie-Leigh Bartleet, Research \& Music Literature, Queensland Conservatorium Griffith University, 140 Grey Street, South Bank, P.O. Box 3428, South Brisbane QLD 4101, Australia.

E-mail: b.bartleet@griffith.edu.au

Andrew R. Brown, Queensland Conservatorium Griffith University, 140 Grey Street, South Bank, P.O. Box 3428, South Brisbane QLD 4101, Australia.

E-mail: andrew.r.brown@griffith.edu.au

Ande Foster, Gympie Flexible Learning Centre, Youth Plus, Edmund Rice Education Australia.

E-mail: ande@soundhive.com 
Kathy Hirche, Queensland University of Technology, Brisbane, Australia.

E-mail: kathyhirche@hotmail.com

Brian Procopis, Sweet Freedom Inc (www.sweetfreedom.org), Coordinator, Community Development Programs, UnitingCare Community, 1/766 Gympie Road, Chermside QLD 4032, Australia.

E-mail: brian.procopis@uccommunity.org.au

S. Alex Ruthmann, University of Massachusetts Lowell, 35 Wilder St., Suite 3, Lowell, MA 01854, USA.

E-mail: alex.ruthmann@gmail.com

Naomi Sunderland, Queensland Conservatorium Griffith University, 140 Grey Street, South Bank, P.O. Box 3428, South Brisbane QLD 4101, Australia.

E-mail: n.sunderland@griffith.edu.au

Notes

${ }^{1}$ The jam2jam family of software allows people to play music and do video remixing together locally or over the Internet (see jam2jam.com).

${ }^{2}$ Other members of the research team were Dr Jennifer Summerville, Dr Marie Knox and John Ong.

${ }^{3}$ Dillon, S., Brader, A. and Adkins, B., The DIScoveringABILITIES Project (research assistant: Amber Hansen).

${ }^{4}$ Burnard and Dillon's report seems to support this statement. 'Ensemble interactions are all too often limited with conventional uses of music technology, which tend to satisfy only the 'self'. Jam 2 jam moves to facilitate ensemble interactions that are more closely akin to live musical transactions such as group performances and band interaction' (2010: $6)$. 
${ }^{5}$ jam2jam grey allows parameters such as pitch, timbre, note density, volume, tempo and duration to be affected. jam2jam AV allows these same audio parameters to be affected along with visual effects such as cross-fade, blur and saturation (Brown and Dillon 2012).

${ }^{6} \mathrm{http}: / /$ www.brisbanepowerhouse.org/

${ }^{7}$ The participants in the PowerJam Workshops attended a one-off workshop of between 60 and 90 minutes in duration. In Burnard and Dillon's study, the participants attended a one-day event that comprised three 45 -minute and one 30-minute segments involving use of jam2jamAV.

${ }^{8}$ Each participant in this study used jam2jamAV for six hours, jamming online.

${ }^{9} \mathrm{http} / /$ explodingart.com/jam2jam/jam2jam/Recipes/Recipes.html 